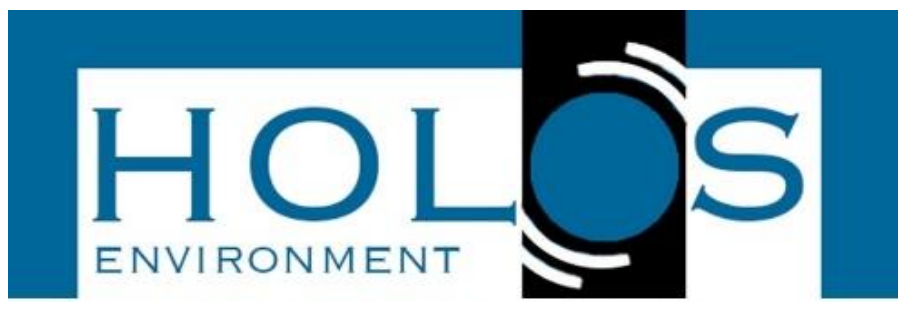

\title{
IMPACTOS AMBIENTAIS CAUSADOS PELA IMPLANTAÇÃO E OPERAÇÃO DE OLARIA EM CAÇAPAVA DO SUL - RS
}

\section{ENVIRONMENTAL IMPACTS CAUSED BY THE DEPLOYMENT AND POTTERY OPERATION IN CAÇAPAVA DO SUL - RS}

\author{
Albert Ayres Landim'; Victor Hugo Braga²; Bruna Antunes de Oliveira²; Ary Sá \\ de Figueiredo²; Pedro Daniel da Cunha Kemerich²; Jorge Eloi Vargas²
}

Artigo recebido em: 24/08/2017 e aceito para publicação em: 10/05/2019.

DOI: http://dx.doi.org/10.14295/holos.v19i1.12216

Resumo: Com o passar dos anos, o crescimento demográfico e o aumento das atividades industriais vêm causando diversos impactos ao meio ambiente, acarretando uma maior preocupação com a preservação ambiental e a saúde da população em geral. Com a finalidade de mitigar ou evitar tais danos, o Estudo de Impacto Ambiental torna-se uma importante ferramenta, possibilitando a implementação de medidas de controle e minimização dos riscos ao meio ambiente. Os impactos causados por olarias resultam na depreciação da qualidade do ar devido ao lançamento de gases e material particulado, além disso, implicam na retirada da vegetação responsável pela cobertura do solo, facilitando a ocorrência de erosões. O presente trabalho teve como objetivo descrever os principais impactos ambientais associados a uma Olaria no município de Caçapava do Sul-RS, apontando possíveis medidas de mitigação e compensação que possam ser adotadas pelo setor. Para a realização deste estudo, foi feito o levantamento da documentação existente do empreendimento, bem como a realização de pesquisa com a comunidade vizinha e visitas no local para a análise das condições ambientais. A avaliação dos impactos gerados durante o processo foi realizada através da utilização de uma Matriz de Identificação de Impactos, possibilitando a relação das atividades exercidas e os possíveis impactos que elas possam gerar no meio biofísico e social. Dessa forma, destaca-se que apesar dos impactos causados pelo processo de produção das peças, o empreendimento proporcionou um desenvolvimento social favorável para a comunidade, promovendo o crescimento urbano e aumento de vagas de empregos para a região.

Palavras-chave: Impactos de Olarias. Estudo de Impacto Ambiental. Desenvolvimento Sustentável.

Abstract: Over the years, population growth and intense industrial activity have caused a lot of impacts on the environment, causing a concern for environmental preservation and the population's health. In order to mitigate or avoid such damage, the environmental impact assessment becomes an important tool, providing implementations of control measures and minimizing risks to the environment. The impacts of brickworks result in depreciation of air quality due to the release of gases and particulate matter, besides, it also results in the removal of vegetation responsible for cover the soil, facilitating the occurrence of. This study aimed to describe the main environmental impacts associated with a pottery in the city of Caçapava do Sul - RS, indicating strategies, mitigation and compensation measures that may be adopted by the industry. For this study it was done a survey of the company's documentation and a research with the surrounding community and on-site visit to evaluate the envi-

\footnotetext{
${ }^{1}$ UFSM - Universidade Federal de Santa Maria (UFSM), Frederico Westphalen, RS. E-mail: (albertlandim.esa@gmail.com)

2 Universidade Federal do Pampa (UNIPAMPA), Caçapava do Sul, RS. E-mail: (victorhbraga@yahoo.com.br, brunaantunesdeoliveira@gmail.com, ary3eng@gmail.com, pedrokemerich@unipampa.edu.br, jorgeeloivargas@yahoo.com.br)
} 
ronmental conditions. The evaluation of impacts generated during the process was accomplished through the use of an Impact Identification Matrix, which made it possible to relate the activities carried out with the impact that they may generate to the biophysical and social environment. It was concluded that despite the impacts caused by the production process, the project has given a favorable social development for the neighboring community, promoting urban growth and increasing jobs for the city.

Palavras-chave: Pottery Impact, Environmental Impact Assessment, Sustainable Development.

\section{INTRODUÇÃO}

O aumento da população mundial levou a um crescimento desordenado das cidades, acarretando em uma alta demanda de materiais utilizados na construção civil, tais como blocos cerâmicos estruturais, blocos de vedação, tijolos, etc. A produção destes materiais ocorre em fábricas denominadas de olarias. As olarias são empreendimentos que podem causar diversos tipos de danos ao meio ambiente, já que no processo de extração, beneficiamento e produção dos tijolos, cerâmicas e afins, são realizadas diversas ações que podem causar impactos maléficos ao meio ambiente e à sociedade.

De acordo com Silva et al. (1993), a atividade de extração desenvolvida no Brasil está voltada principalmente para a produção de matérias-primas para a construção civil, como areia, brita e a argila; e em menor escala são produzidos caulim, feldspato e quartzito. O autor comenta, ainda, que apesar das explorações minerais serem muito importantes para a construção civil, não se deve deixar de lado o impacto que geram na paisagem e os cuidados que deve-se ter com a extração, tendo em vista os possíveis usos futuros do solo explorado. Segundo Suzumura et al. (2007), a degradação durante a exploração mineral ocorre quando a mesma é exercida sem as técnicas adequadas, o que tem provocado grandes prejuízos ao meio ambiente. A poluição visual e sonora, a ameaça às edificações, as áreas desmatadas, o surgimento de erosões e outros problemas causados à paisagem são exemplos de complicações que poderiam ser evitadas a partir de um correto exercício das atividades do estabelecimento.

No processo de extração da argila é realizado o processo de decapeamento do solo, causando o processo de erosão e alteração da paisagem. Na medida em que o solo vai sendo retirado, o lençol freático torna-se mais vulnerável, facilitando a contaminação das águas subterrâneas, caso ocorram derramamentos de óleo ou derivados provenientes do maquinário empregado no local. De acordo com Bitar 
(1997), a degradação de uma área ocorre quando a vegetação nativa e a fauna forem destruídas, removidas ou expulsas; a camada fértil do solo for perdida, removida ou enterrada; e a qualidade, ou o regime de vazão, do sistema hídrico forem alterados. Já a degradação ambiental ocorre quando há perda de adaptação às características físicas, químicas e biológicas.

Além do impacto descrito, ainda podem ocorrer ressuspensão de Material Particulado (MP) e emissão de gases poluentes causados pelo fluxo de veículos no local (como por exemplo o tráfego de caminhões), geração de impactos visuais, acúmulo de resíduos provenientes da produção e, ainda, a ocorrência de ruídos e vibrações causadas pelas máquinas responsáveis pela extração, produção e transporte do material produzido. Conforme Kemerich et al. (2011), todo ou qualquer empreendimento causa algum tipo de impacto ambiental, e este impacto pode agredir tanto o solo, a água e/ou o ar atmosférico em conseqüência dos processos, desde a instalação até o produto final gerado pelo empreendimento. Estes impactos podem ser enquadrados como impacto de grande, média ou pequena magnitude, sendo possível minimizá-los ou compensá-los com o intuito de deixar a área atingida similar ao que era anteriormente à instalação do empreendimento.

Conforme a Resolução no 01 de 23 de janeiro de 1986 do Conselho Nacional do Meio Ambiente - CONAMA, é possível considerar impacto ambiental como sendo qualquer alteração das propriedades físicas, químicas e biológicas do meio ambiente causada por qualquer tipo de matéria ou energia resultante das atividades humanas, de forma direta ou indireta. Com isso, foi desenvolvido na década de 70, nos Estados Unidos, a Avaliação de Impactos Ambientais, tornando-se um importante instrumento da política ambiental. Desde o inicio do processo, realiza-se exames avaliativos dos impactos ambientais causados por determinadas ações, buscandose alternativas para minimizar ou compensar tais impactos (SANCHEZ, 2015).

Segundo Mendonça (2006), no processo de extração da argila, a cobertura vegetal é geralmente retirada totalmente e armazenada, para posterior utilização na recuperação da própria área após o término da extração. Porém, este é um impacto relevante e que deve ser destacado, no qual o solo ficará exposto às condições climáticas, podendo assim promover a erosão do mesmo e a alteração da paisagem. Além disso, com a retirada da cobertura vegetal e a modificação do relevo natural, as espécies presentes também podem ser prejudicadas, tendo em vista que seu habitat é alterado, dificultando a sobrevivência das mesmas no local. 
As atividades de transporte da matéria prima e do produto final podem ocasionar danos nas proximidades das áreas de tráfego causados pela intensificação da vibração gerada pelos caminhões. De acordo com Souza et al. (2015) a vibração induzida nas edificações pode gerar danos estruturais em algumas situações, dependendo de fatores como a intensidade da vibração, a formação geológica local, o padrão arquitetônico das edificações, a velocidade de fluxo de veículos nas vias próximas e a qualidade de pavimentação das mesmas.

Pelo conjunto de preocupações relacionadas aos impactos ambientais cometidos pelas atividades da indústria oleira, é de suma importância a identificação e a análise dos principais prejuízos ao meio ambiente ocasionados nesta atividade. Diante disto, o objetivo deste trabalho foi avaliar os impactos ambientais gerados pela operação de uma olaria do interior do estado do Rio Grande do Sul, no município de Caçapava do Sul.

\section{DESCRIÇÃO DO EMPREENDIMENTO E PROCESSOS}

\subsection{Empreendimento e Área de Estudo}

O trabalho foi realizado em uma olaria responsável pela extração e beneficiamento de argila, localizada no município de Caçapava do Sul. O município em que o empreendimento está estabelecido situa-se próximo à região central do estado do Rio Grande do Sul, com área de $3.047,113 \mathrm{~m}^{2}$ e uma população de 33.690 habitantes, conforme os dados fornecidos por IBGE (2010). A empresa estudada foi fundada em março de 1996, possuindo atualmente 18 funcionários distribuídos nos setores de extração, beneficiamento, direção e vendas. A área total do empreendimento é de 5,8 hectares. A região em que ocorre a atividade de extração, a produção das peças e a localização da sede é caracterizada pelo Bioma Pampa (IBGE, 2004). A vegetação local é pertencente ao tipo "Estepe Parque", a qual é conhecida por ser uma vegetação essencialmente campestre, com predominância de gramíneas e ocorrência de espécies lenhosas deciduais espinhosas.

A sede da olaria, ilustrada na Figura 1, possui secretaria, departamento de vendas, área de beneficiamento e depósito; totalizando 4.016,71 $\mathrm{m}^{2}$ de área construída. Localiza-se no KM 04 da RS 357, Esquina do Segredo, no município 
citado. Suas coordenadas geográficas são: $30^{\circ} 33^{\circ} 33^{\prime} 20,03.9^{\prime \prime}$ e $53^{\circ} 30^{\prime} 59.0^{\prime \prime}$ W. Já a Figura 2 apresenta a jazida de extração da argila, situada no KM 08 da RS 357, entre Lavras do Sul e a sede do município na Coxilha de São José, ainda no município de Caçapava do Sul. Esta área possui aproximadamente 11 hectares. Suas coordenadas geográficas são $30^{\circ} 34^{\prime} 58,8^{\prime \prime}$ S e $53^{\circ} 31^{\prime} 04,1^{\prime \prime}$ W.

Figura 1 - Sede da Olaria (imagem adquirida do Figura 2 - Jazida de Argila (imagem adquirida Google Earth)

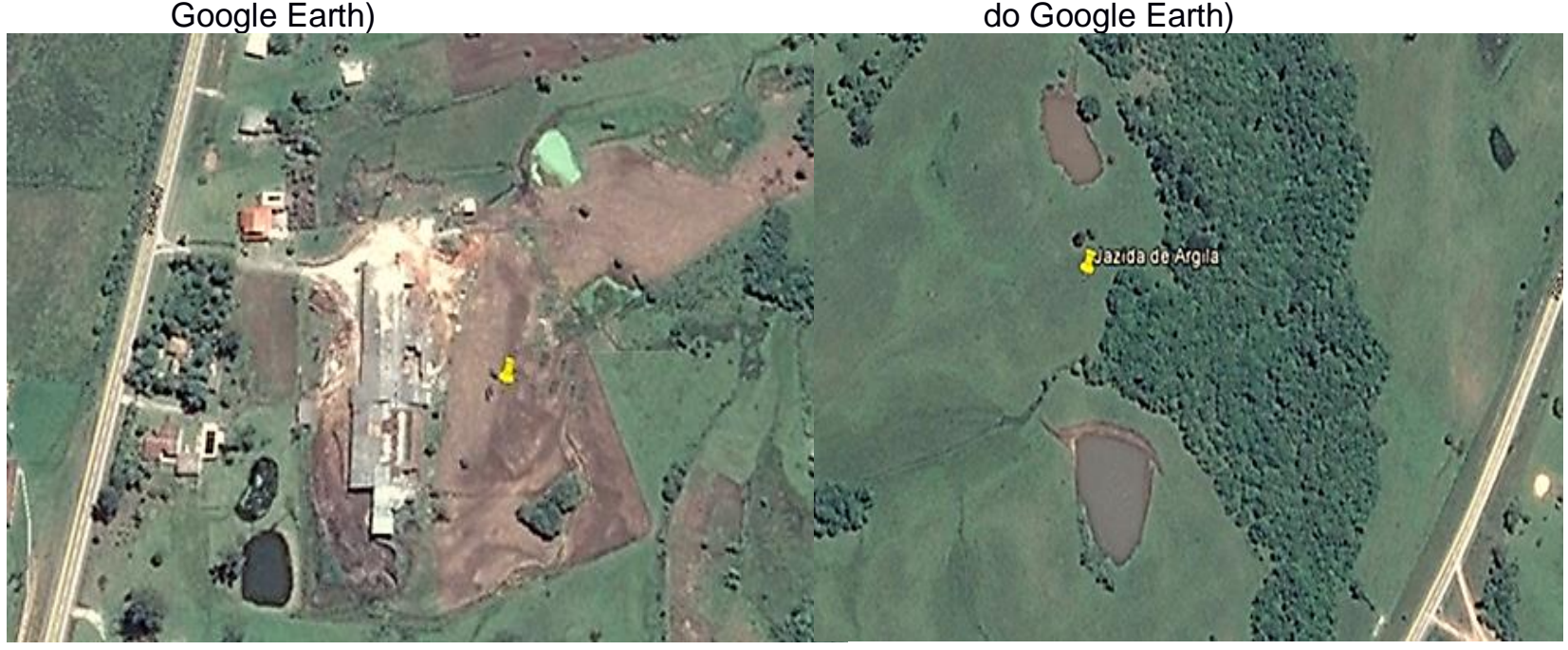

O principal objetivo do empreendimento é a produção de blocos estruturais, blocos de vedação, tijolos e peças essenciais para as atividades da construção civil, através da extração da matéria prima. Sua matéria prima é constituída principalmente de argilas vermelhas (argissolos vermelhos e pretos), formados a partir de iluviação, levando-se em consideração que a argila preta apresenta características mais arenosas que a argila vermelha.

\subsection{Extração da Argila}

As áreas de extração do empreendimento foram escolhidas através de prévio estudo geológico e de viabilidade ambiental, tendo sido constatada a existência de argila vermelha e argila preta no local (a composição desses dois tipos de argila formam a argila ideal para a produção). As cavas utilizadas atualmente estão em conformidade com a norma NBR-11.682 da ABNT de setembro de 1991.

A área de retirada da argila é uma propriedade particular, desprovida de vegetação lenhosa, contendo apenas gramíneas. Tendo isto em vista, não há a necessidade de remoção das espécies nativas da flora, evitando-se a degradação 
da fauna local. Para a remoção da argila, inicia-se com o processo de decapeamento da camada superficial do solo, composta por solo orgânico. Somente após a conclusão dessa etapa é que se inicia a extração da argila, na qual são utilizadas a retroescavadeira, a pá carregadeira e as caçambas, além da utilização de tratores com lâmina frontal e niveladora. O solo removido é armazenado para posterior reutilização na recuperação da própria área após o término da extração da argila.

\subsection{Produção das Peças}

Após a extração, a argila é transportada e armazenada em um depósito ao ar livre, onde são montadas as chamadas "tortas". Estas "tortas" consistem em uma mistura de 60\% argila preta e $40 \%$ de argila vermelha, mantendo-se $20 \%$ de umidade. As misturas então ficam em repouso de quatro a seis meses. Geralmente são feitas cinco tortas e, enquanto algumas estão repousando, as outras são levadas para um depósito na parte interna do empreendimento.

A argila então é depositada por uma escavadeira em caixas alimentadoras, as quais são conduzidas através de esteiras. Esta argila passa ainda por uma prensa para ser compactada. Após a compactação, a argila é direcionada para as formas, nas quais são geradas os blocos contínuos que, logo após, são recortados por fios de aço, totalizando oito blocos em argila crua.

Em seguida, os blocos de argila são transportados até prateleiras móveis. Essas prateleiras são conduzidas mecanicamente através de trilhos para uma câmara de estufa, onde será realizada a pré-secagem com uma temperatura constante de cinquenta graus centígrados por um período de quarenta e cinco horas. Passadas as quarenta e cinco horas, os blocos são retirados e acondicionados a fim de manter o calor, antes de serem levados ao forno. $O$ processo final de cozimento é realizado em um forno automatizado, mostrado na Figura 3, que atinge uma temperatura de oitocentos e cinquenta graus na zona de queima, permanecendo por até 72 horas. Após a saída do forno, as peças permanecem armazenadas nas prateleiras por um momento, a fim de diminuir a temperatura, poderem ser classificadas e depois enviadas ao depósito para posterior comercialização. 
Figura 3 - Forno de Queima Horizontal

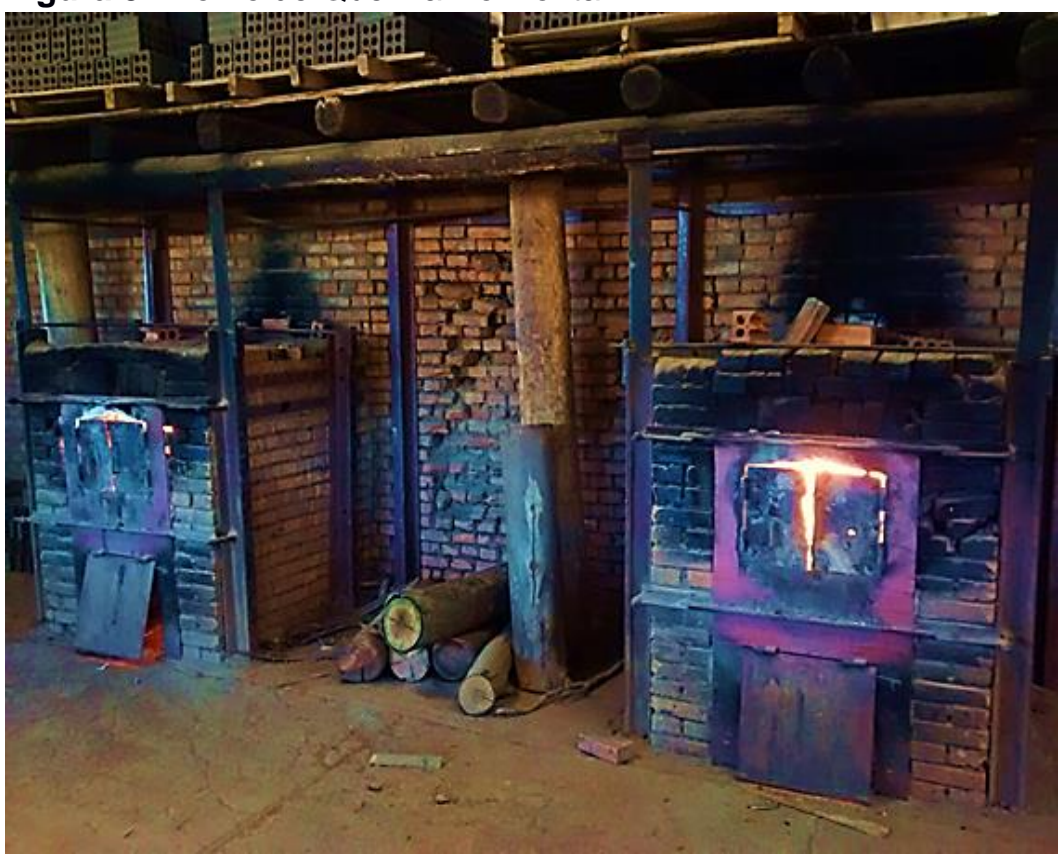

\section{METODOLOGIA}

Para o levantamento dos dados foram confeccionados questionários do tipo múltipla escolha para serem respondidos pelo responsável pelo estabelecimento, contendo questões relativas aos processos exercidos na olaria. No quadro 1 são apresentadas algumas das questões aplicadas à direção do empreendimento.

Quadro 1 - Parte do questionário aplicado ao responsável pelo estabelecimento

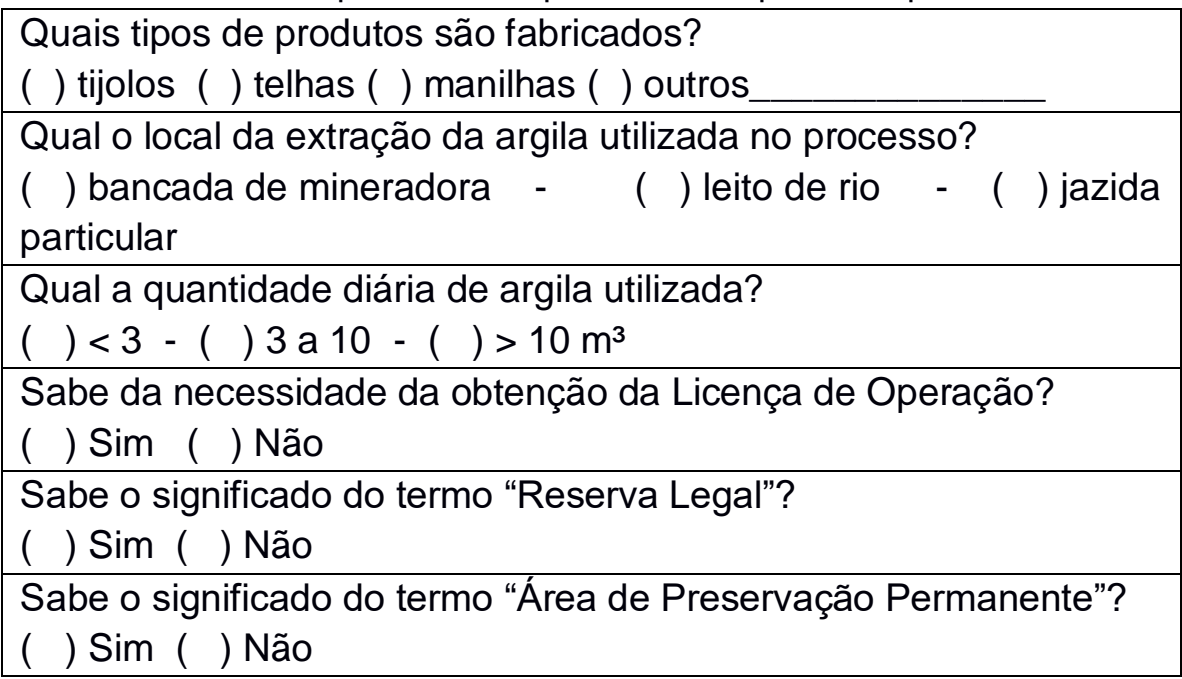

Além disso, foram aplicados questionários a todos os funcionários que estavam no local, abordando sobre questões relativas ao grau de educação, 
treinamentos, condições de trabalho, entre outras. No quadro 2 são mostradas algumas questões que foram realizadas.

Quadro 2 - Parte do questionário aplicado aos funcionários do estabelecimento

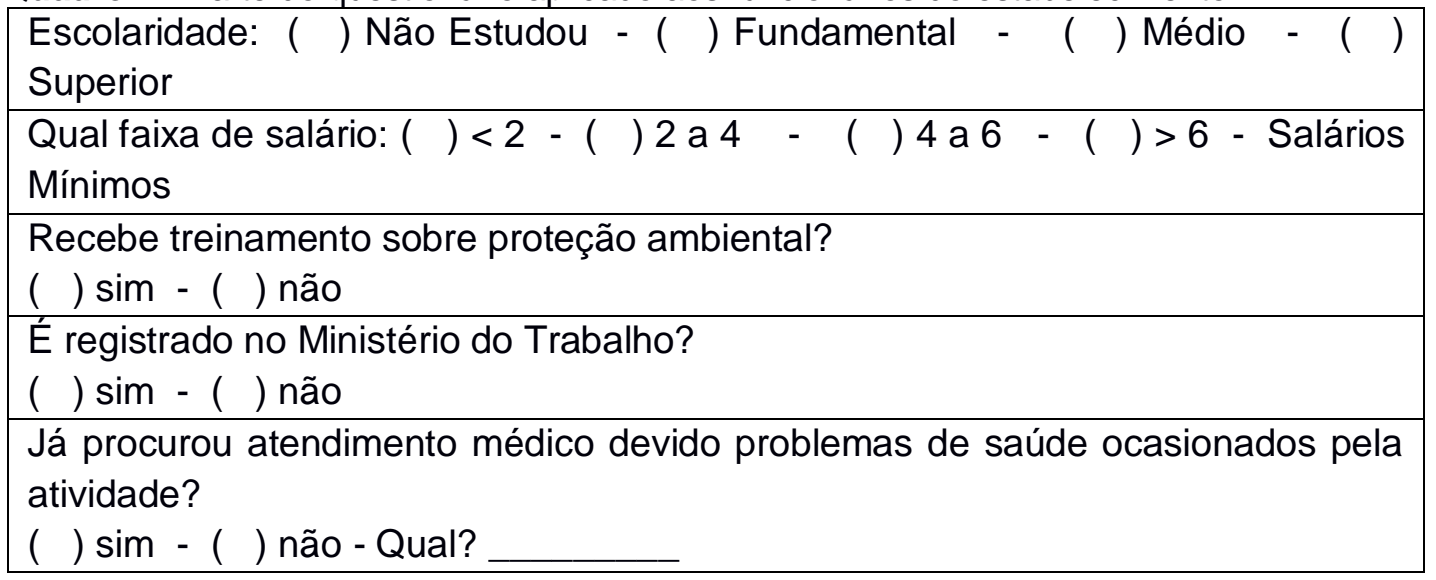

Ainda, foi realizada entrevista com a comunidade local através da aplicação de um terceiro questionário de múltipla escolha (Quadro 3) abordando assuntos como possíveis incômodos provocados pelo estabelecimento, condições de saúde e parentesco com funcionários de empresas do ramo de olarias.

Quadro 3 - Parte do questionário aplicado na comunidade local

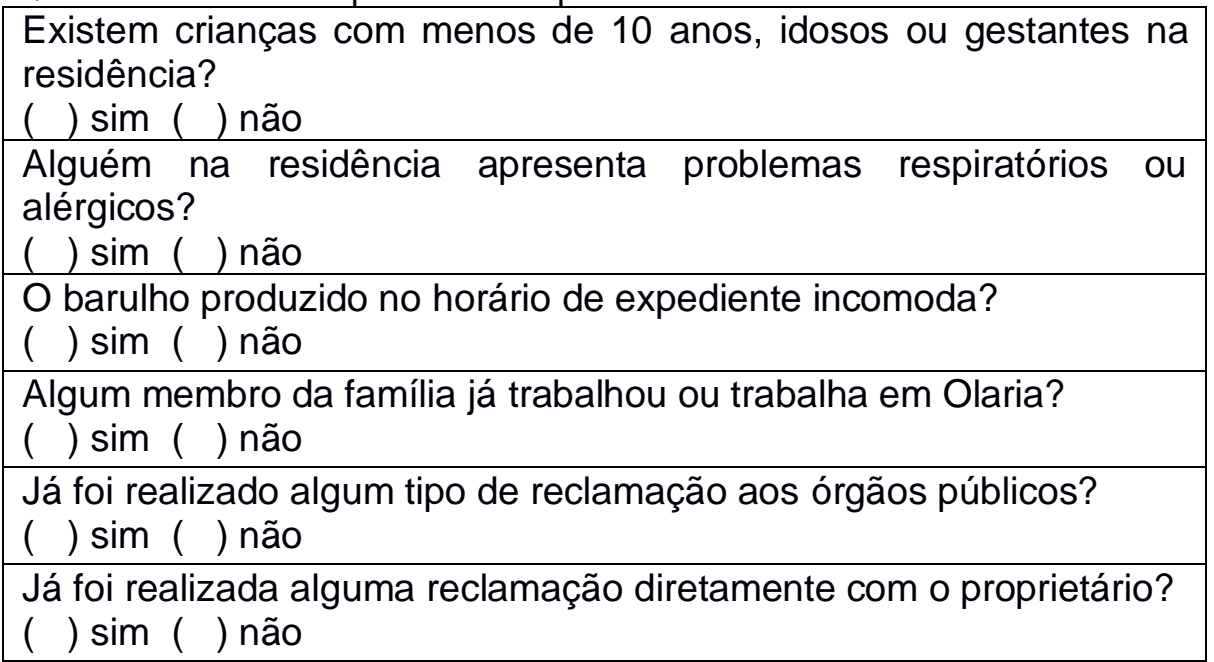

Além dos questionários, também foram elaboradas planilhas utilizadas durante a visita, tendo o objetivo de realizar o levantamento de dados referentes às condições das instalações e da documentação existente, conforme demonstrado no quadro 4. 
Tabela 4 - Planilha para levantamento de dados preenchida durante a visita no estabelecimento

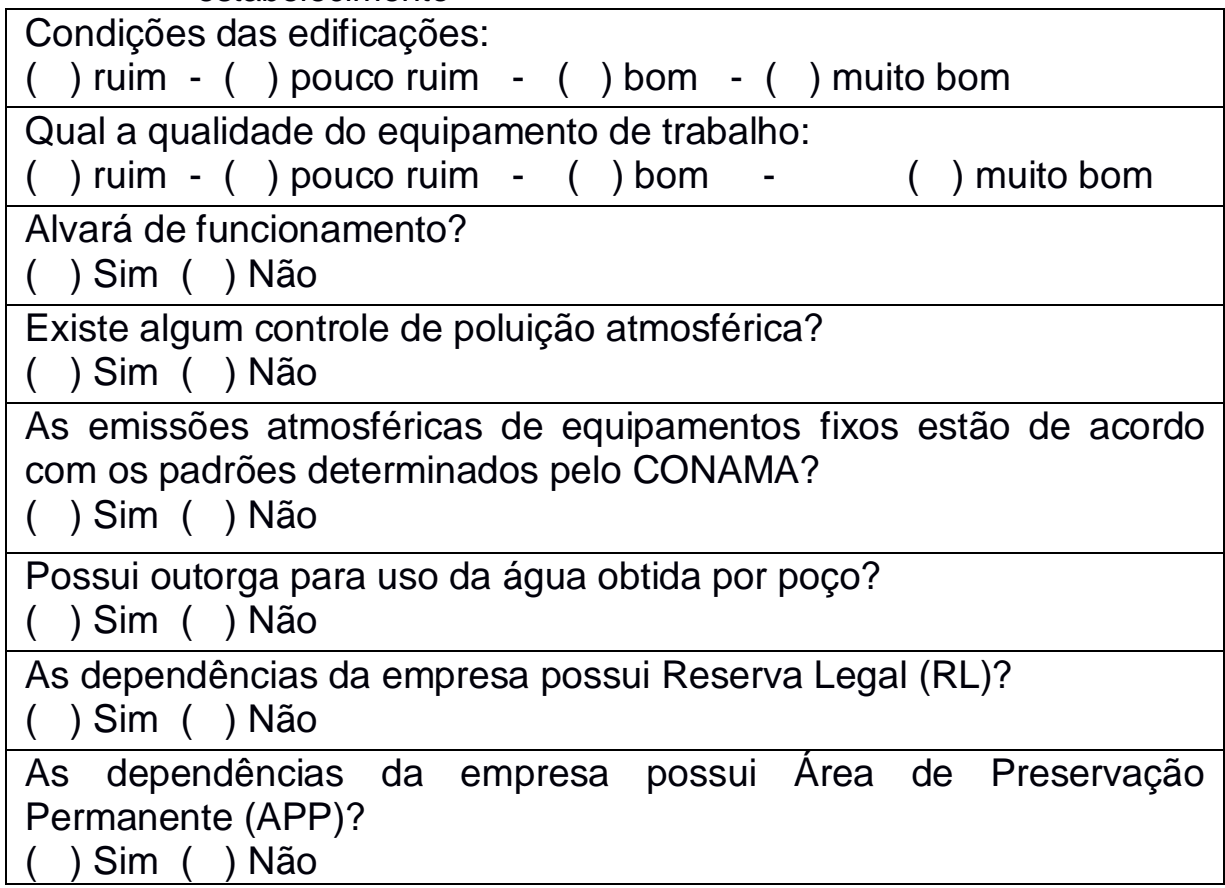

Logo após a elaboração do material de apoio, foi agendada a visita técnica à empresa. Durante a visita foram preenchidas as planilhas, aplicando-se os questionários e efetuando-se registros fotográficos dos processos de fabricação, dos locais de trabalho e das condições do ambiente. Para a avaliação dos impactos ambientais (AIA), foi confeccionada uma Matriz de Identificação de Impactos (com adaptações) conforme descrita por Sanchez (2015), dispostas por linhas e colunas que consistem em duas listagens de controle, uma que lista as atividades do projeto associadas aos aspectos ambientais, tais como uso do solo ou consumo de recursos, e outra onde são selecionados os impactos ambientais que podem ser afetados por estas atividades, permitindo a identificação das possíveis interações entre os componentes dos processos produtivos.

Segundo Carvalho et al. (2010), a utilização das matrizes geralmente desencadeia uma melhora na análise qualitativa, destacado-se os seguintes atributos de impactos: tipo de ação: ignição, sinergia e criticidade; extensão, periodicidade e intensidade. Este método permite uma fácil compreensão dos resultados, aborda aspectos dos meios físico, biótico e socioeconômico, comporta dados qualitativos e quantitativos, além de fornecer orientação para a continuidade dos estudos e favorecer a multidisciplinaridade. 
Uma vez selecionadas as ações e os componentes ambientais pertinentes, foram identificadas todas as possíveis interações. As cores inseridas em cada célula correspondem à pontuação de magnitude e à importância da interação em uma escala de: Classificação de aspectos (0 a 1 - não significativo, 2 - aspecto pouco significativo, 3 a 4 - aspecto muito significativo); classificação de impactos (vermelho: impacto muito importante; amarelo: impacto pouco importante; sem preenchimento: não há interação). A classificação de aspectos é apontada no canto superior esquerdo da célula, enquanto que a atividade localiza-se na coluna central e seus impactos ocupam o lado direito da matriz.

\section{RESULTADOS E DISCUSSÃO}

\subsection{Resultados da Pesquisa}

Para a confecção da Matriz foram utilizados dados obtidos durante a visita, no momento em que foi apresentada a documentação e averiguada as condições de operação da olaria, tendo sido levado em consideração também a pesquisa com os funcionários e com a comunidade vizinha. Foi constatado que a empresa possui o Alvará de Funcionamento e que foram realizados a Licença de Instalação, o Estudo de Impacto Ambiental e o Relatório de Impacto Ambiental. Contudo, no momento da pesquisa, a Licença de Operação encontrava-se vencida e não possuía Outorga para o uso da água. De acordo com o proprietário, a empresa possui Reserva Legal e Área de Preservação Permanente em suas dependências, estando com as emissões atmosféricas dentro dos padrões determinados pela Resolução ํㅡ응 03 de 28/06/1990 do CONAMA.

Os dados obtidos na pesquisa realizada mostrou que dentre os 18 funcionários, todos são registrados no Ministério do Trabalho e Emprego (MTb) e, também, são todos do sexo masculino com idades predominantes entre 21 e 40 anos. Dentre eles, 5 são fumantes e mais de $90 \%$ possuem apenas o ensino fundamental completo. A faixa salarial predominante é de até 2 salários mínimos, sendo que menos de 10\% recebem até 4 salários mínimos, e ainda, $70 \%$ dos funcionários residem à uma distância superior a $1 \mathrm{~km}$ do local de trabalho. Além disso, mais de $60 \%$ do quadro tem entre 4 e 5 anos de prestação de serviço nessa mesma olaria, enquanto que $27 \%$ deles não tem experiência no ramo oleiro. Menos 
de $40 \%$ receberam treinamento sobre Preservação Ambiental antes de começar suas atividades. Porém, o fator mais preocupante percebido é que, dos funcionários que sofreram algum tipo de problema de saúde relacionado com as atividades laborais, $90 \%$ não procuraram atendimento médico, já o restante procurou atendimento devido a problemas de dores musculares e dores nas costas.

A pesquisa realizada na vizinhança contou com um universo de 32 residências, as quais $96 \%$ localizam-se a menos de 500 metros de distância do estabelecimento. Do total das residências amostradas, 11 possuem moradores menores de 10 anos ou maiores de 60, sendo que em 7 haviam pessoas com problemas respiratórios. Houveram duas reclamações por parte dos moradores, uma relacionada ao barulho emitido durante horário de funcionamento e outra devido a fumaça emitida pelos caminhões. Também, $12 \%$ das residências relataram que ocorrem atividades antes das 7:00 horas e após as 18:00 no empreendimento, ou seja, fora de horário comercial. Ademais, 60\% confirmaram que possuem algum membro que trabalha ou já trabalhou na olaria e 100\% dos entrevistados conhecem alguém que trabalha ou já trabalhou na olaria.

\subsection{Avaliação de Impacto Ambiental}

Fundamentada na matriz original de Leopold (1971), buscou-se desenvolver uma matriz que relacionasse de forma direta os impactos ambientais, sejam em meio biofísico ou em meio antrópico, e os aspectos ambientais/sociais causados pela olaria avaliada. A Matriz de Leopold, com diversas variantes, tem sido utilizada em estudos, procurando associar os impactos de uma determinada ação de um empreendimento com as diversas características ambientais de sua área de influência (MOTA, 2002).

Assim, através do preenchimento da Matriz de Identificação de Impactos causados pelo empreendimento, foi possível avaliar os possíveis danos associados às diversas atividades que compreendem o processo de fabricação. Conforme descrito anteriormente, a matriz foi dividida em atividades associadas aos Aspectos Socioambientais e os impactos provenientes destes aspectos, conforme mostrado na Figura 4. 
Figura 4 - Matriz de avaliação de impacto ambiental para a produção de tijolos

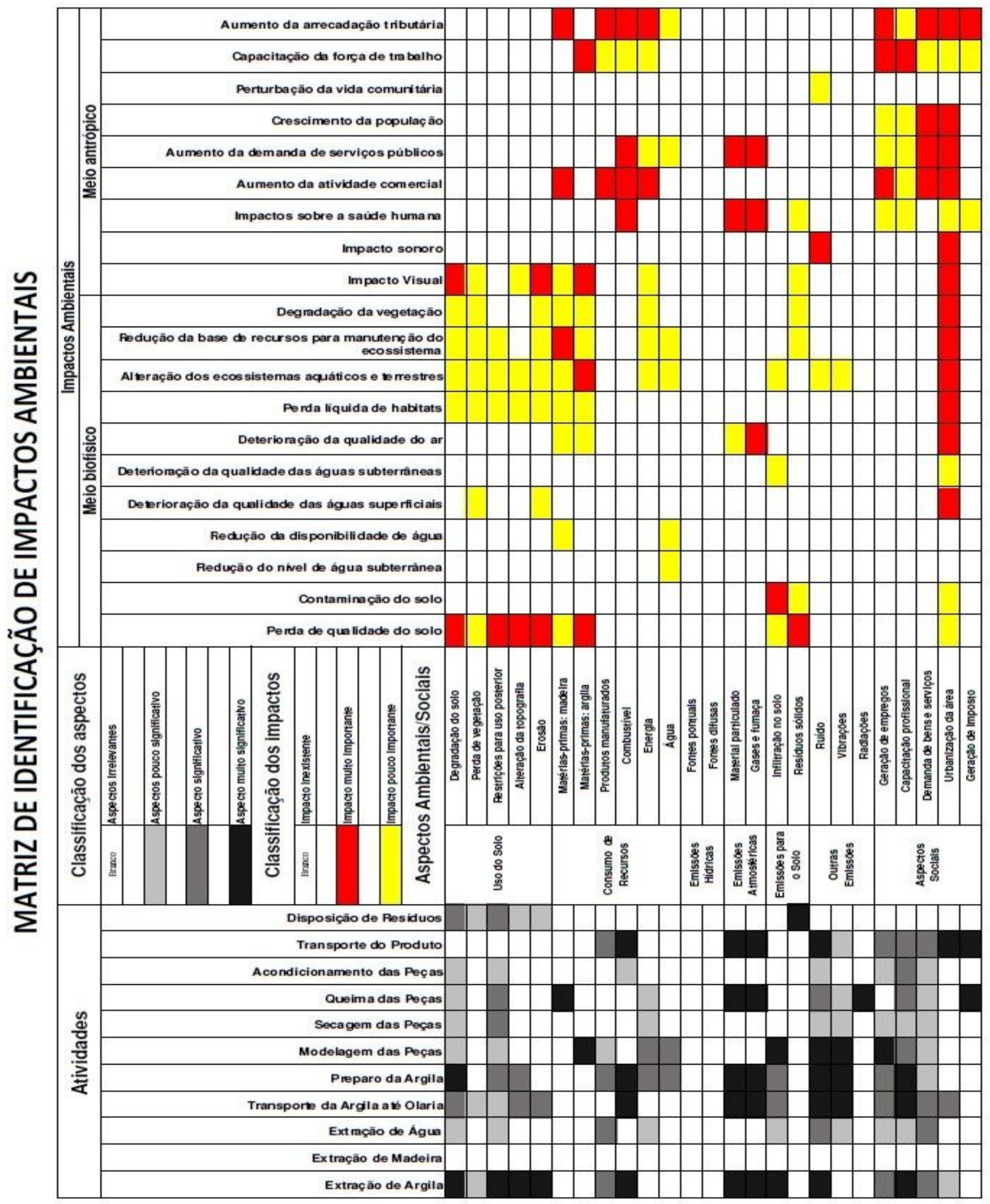




\subsection{Aspectos Socioambientais $\mathrm{x}$ Impactos Ambientais}

No quadro 6 são apresentados os Impactos Ambientais relevantes em função das classificações dos Aspectos Socioambientais:

Quadro 5 - Aspectos Ambientais / Sociais x Impactos Ambientais

\begin{tabular}{|c|c|}
\hline IMPACTOS & ASPECTOS \\
\hline $\begin{array}{l}\text { Perda da } \\
\text { Qualidade do } \\
\text { Solo }\end{array}$ & $\begin{array}{l}\text { Ocorre devido à degradação do solo, causando restrições para o uso } \\
\text { posterior, alteração da topografia e erosão decorrentes do processo de } \\
\text { retirada da camada superficial e aprofundamento do mesmo. É decorrente } \\
\text { também devido ao grande consumo de matéria prima, no caso, a argila. }\end{array}$ \\
\hline $\begin{array}{l}\text { Contaminação } \\
\text { do Solo }\end{array}$ & $\begin{array}{l}\text { Pode ocorrer devido à infiltrações no solo provenientes de vazamentos de } \\
\text { óleo dos equipamentos. }\end{array}$ \\
\hline $\begin{array}{l}\text { Deterioração da } \\
\text { Qualidade das } \\
\text { Águas } \\
\text { Superficiais }\end{array}$ & $\begin{array}{l}\text { Apresenta um impacto muito relevante, já que a urbanização da área em } \\
\text { torno da olaria (causada pelo aumento da população) acaba gerando } \\
\text { esgotos que muitas vezes são lançados in natura, sem nenhum tipo de } \\
\text { tratamento. }\end{array}$ \\
\hline $\begin{array}{l}\text { Deterioração da } \\
\text { Qualidade do Ar }\end{array}$ & $\begin{array}{l}\text { Apresenta impacto muito relevante devido ao lançamento de gases e } \\
\text { fumaça originados pelos veículos do empreendimento e, também, no } \\
\text { processo de queima das peças. As emissões de material particulado gerado } \\
\text { no processo são reduzidas com a utilização de filtros instalados na saída } \\
\text { das chaminés. }\end{array}$ \\
\hline $\begin{array}{l}\text { Alteração dos } \\
\text { Ecossistemas } \\
\text { Aquáticos e } \\
\text { Terrestres }\end{array}$ & $\begin{array}{l}\text { Possui impacto muito relevante, devido a retirada do solo orgânico } \\
\text { promover a alteração no microambiente, alterar a estrutura dos horizontes e } \\
\text { interferir na topografia da região. }\end{array}$ \\
\hline Impacto Visual & $\begin{array}{l}\text { Ocasiona impacto muito importante, decorrente da degradação do solo e } \\
\text { erosões que são gerados pelo consumo de matéria prima, através do } \\
\text { processo de extração da argila, além do incentivo à urbanização da área, } \\
\text { alterando o ambiente natural da região. }\end{array}$ \\
\hline Impacto Sonoro & $\begin{array}{l}\text { É provocado pelos ruídos emitidos no funcionamento dos equipamentos de } \\
\text { modelagem e pelos tratores e caminhões que atuam no local de extração, } \\
\text { preparo da argila e no transporte. É classificado como muito relevante, pois } \\
\text { o ruído provocado por rodovias prejudica a população de pássaros nas } \\
\text { proximidades, como mostrado por Summers et al. (2011). }\end{array}$ \\
\hline $\begin{array}{l}\text { Impactos Sobre } \\
\text { a Saúde } \\
\text { Humana }\end{array}$ & $\begin{array}{l}\text { Pelas emissões de gases e materiais particulados, é ocorrido um detrimento } \\
\text { da saúde humana conforme estudo realizado por Morawska et al. (2008), } \\
\text { desta forma, tal impacto foi classificado como muito relevante. }\end{array}$ \\
\hline $\begin{array}{l}\text { Aumento da } \\
\text { Atividade } \\
\text { Comercial }\end{array}$ & $\begin{array}{l}\text { Promove um impacto muito relevante na sociedade, devido ao consumo de } \\
\text { recursos como: madeira, produtos manufaturados, combustível e energia } \\
\text { elétrica. Além disso, gera impactos muito importantes nos aspectos sociais } \\
\text { pela geração de empregos, demanda de bens e serviços e urbanização da } \\
\text { área. }\end{array}$ \\
\hline $\begin{array}{c}\text { Aumento da } \\
\text { Demanda de } \\
\text { Serviços } \\
\text { Públicos } \\
\end{array}$ & $\begin{array}{l}\text { Há aumento na demanda por serviços de abastecimento, energia elétrica e } \\
\text { vários outros associados ao crescimento da urbanização. Por tais motivos, } \\
\text { esse impacto é considerado muito relevante. }\end{array}$ \\
\hline
\end{tabular}


Quadro 5 - Aspectos Ambientais / Sociais x Impactos Ambientais

\begin{tabular}{|c|c|}
\hline \begin{tabular}{c} 
Quadro 5 - Aspectos Ambientais / Sociais x Impactos Ambientais \\
\hline IMPACTOS
\end{tabular} & \multicolumn{1}{c|}{ ASPECTOS } \\
\hline $\begin{array}{c}\text { Crescimento da } \\
\text { População }\end{array}$ & $\begin{array}{l}\text { Gera impactos significativos nos aspectos sociais, pois ocorre um aumento } \\
\text { na demanda de bens e serviços e urbanização da área. }\end{array}$ \\
\hline $\begin{array}{c}\text { Capacitação da da } \\
\text { Força de } \\
\text { Trabalho }\end{array}$ & $\begin{array}{l}\text { Gera um impacto muito relevante, pois no processo de extração de argila, } \\
\text { transporte e acondicionamento das peças, o operador deve ter a } \\
\text { qualificação necessária para operar trator, caminhão e/ou empilhadeiras, } \\
\text { incentivando a capacitação profissional. }\end{array}$ \\
\hline $\begin{array}{c}\text { Aumento da } \\
\text { Arrecadação } \\
\text { Tributária }\end{array}$ & $\begin{array}{l}\text { Com o consumo de madeira, produtos manufaturados, combustível e e } \\
\text { energia, além do aumento na geração de empregos, demanda de bens e } \\
\text { serviços, urbanização da área e geração de empregos, é ocasionado um } \\
\text { impacto muito relevante. }\end{array}$ \\
\hline
\end{tabular}

\section{CONCLUSÕES}

De acordo com a Matriz de Identificação de Impactos, foi possível obter um melhor entendimento dos danos causados pelo processo de extração da argila, queima e transporte das peças. Alguns pontos chamaram a atenção devido ao agravamento da situação, como por exemplo, as condições dos equipamentos que continham vazamentos de óleo e a ausência de providências para contê-los ou, ao menos, reduzi-los. Outras ocorrências preocupantes notadas foram a remoção da camada de solo orgânico, que se não for reposta pode facilmente permitir ocorrências de erosões, e as emissões de gases e partículas originadas pelo processo de queima das peças e pelo uso dos veículos. Os impactos que podem ser descartados foram associados à contaminação das águas subterrâneas e à diminuição da disponibilidade do nível do lençol freático, em virtude da pequena quantidade de água utilizada proveniente destas fontes. Além disso, analisando-se os questionários realizados com a comunidade vizinha, percebeu-se que a vida na comunidade não sofre impactos negativos relevantes. Por fim, apesar dos aspectos negativos abordados, ressalta-se a importante contribuição da olaria para a sociedade através da geração de empregos, incentivo à qualificação profissional e aumento de impostos arrecadados, os quais são revertidos para melhorias na região, impulsionando o desenvolvimento da comunidade em que o empreendimento está localizado.

\section{REFERÊNCIAS}

ASSOCIAÇÃO BRASILEIRA DE NORMAS TÉCNICAS. NBR 11.682: Estabilidade de taludes. Rio de Janeiro: ABNT, 1991.. 
BITAR, O. Y. Avaliação da recuperação de áreas degradadas por mineração na região metropolitana de São Paulo. 1997. Tese (Doutorado) - Universidade de São Paulo.

BRASIL. Conselho Nacional do Meio Ambiente. Resolução. 1/86, de 23 de janeiro de 1986. Dispõe sobre procedimentos relativos a Estudo de Impacto Ambienta. O Conselho Nacional do Meio Ambiente CONAMA, 1986.

BRASIL. Conselho Nacional do Meio Ambiente. Resolução no 003, de 28 de junho de 1990. Dispõe sobre os Padrões de Qualidade do Ar. Diário Oficial da União, Brasília, DF, 22 de agosto de 1990, Seção 1, páginas 15937-15939

CARVALHO D. L. et al. Metodologias para Avaliação de Impactos Ambientais de Aproveitamentos Hidrelétricos. In: ENCONTRO NACIONAL DOS GEÓGRAFOS. CRISE, PRÁXIS E AUTONOMIA: ESPAÇOS DE RESISTÊNCIA E DE ESPERANÇAS. 26., 2010. Anais... Porto Alegre. 2010.

INSTITUTO BRASILEIRO DE GEOGRAFIA E ESTATíSTICA. Dados do Censo 2010. Rio de Janeiro. IBGE, 2010.

INSTITUTO BRASILEIRO DE GEOGRAFIA E ESTATÍSTICA. Mapa de vegetação do Brasil e biomas do Brasil. Rio de Janeiro. IBGE, 2004.

KEMERICH, P. D. C. et al. Avaliação de impactos ambientais na implantação e operação de olaria. Engenharia Ambiental - Espírito Santo do Pinhal, v. 8, n. 1, p. 134-150, 2011.

LEOPOLD, L. B. A procedure for evaluating environmental impact. US Dept. of the Interior, 1971.

MENDONÇA, B. et al. Ambiente de Olaria: Cidadania a prova. Universidade Regional Integrada do Alto Uruguai e das Missões, Santo Ângelo, RS, 2006.

MORAWSKA, L. et al. Ambient nano and ultrafine particles from motor vehicle emissions: Characteristics, ambient processing and implications on human exposure. Atmospheric Environment, v. 42, n. 35, p. 8113-8138, 2008.

MOTA, S. et al. Proposta de uma matriz para avaliação de impactos ambientais. In: SIMPÓSIO ITALO BRASILEIRO DE ENGENHARIA SANITÁRIA E AMBIENTAL, 6., 2002. Anais... ABES, 2002. p. 1-9.

SÁNCHEZ, L. E. Avaliação de impacto ambiental. Oficina de Textos, 2015.

SILVA, AA da et al. Mineração no município de São Paulo: aspectos legais e sócioambientais-SAR. Prefeitura do Município de São Paulo/Secretaria Municipal do Verde e do Meio Ambiente. A questão ambiental urbana: cidade de São Paulo. São Paulo, p. 348-64, 1993.

SOUZA, L. E. et al. Avaliação de impacto relacionado com ruído e vibração em perímetro urbano. Monografias Ambientais, p. 33-43, 2015.

SUMMERS, P. D.; CUNNINGTON, Glenn M.; FAHRIG, Lenore. Are the negative effects of roads on breeding birds caused by traffic noise?. Journal of Applied Ecology, v. 48, n. 6, p. 1527-1534, 2011.

SUZUMURA, G.Y.R.; SOUZA, S.K.P. de. Explorações minerais e seu impacto sobre a paisagem paulistana. Iniciação Científica. Ano I, n. 1, p. 07-16, 2007. 